\title{
2006-2498: USING A SYSTEMS ENGINEERING APPROACH TO TEACH MIDDLE SCHOOL SCIENCE CONCEPTS
}

\section{Matthew Mehalik, University of Pittsburgh}

Matthew Mehalik is Visiting Assistant Professor of Industrial Engineering and Research

Associate at the Learning Research and Development Center, University of Pittsburgh

\section{Yaron Doppelt, University of Pittsburgh}

Yaron Dopplet is a Postdoctoral Associate at the Learning Research and Deverlopment Center at the University of Pittsburgh

\section{Christian Schunn, University of Pittsburgh}

Christian Schunn is Assistant Professor of Intelligent Systems and Psychology and Research Scientist at the Learning Research and Development Center, University of Pittsburgh 


\section{Using a Systems Engineering Design Approach to Teach Middle School Science Concepts}

\section{Abstract}

This paper contrasts performance overall and by gender, ethnicity, and SES for middle school students learning science through traditional scripted inquiry versus a systems engineering, design-based approach, in which students designed and built electrical alarm systems to learn electricity concepts over a 4-week period using authentic engineering design methods. The contrast study took place in the $8^{\text {th }}$ grade of an urban, public school district, with the systems approach implemented in 26 science classes (10 teachers and 587 students) and the scripted inquiry approach implemented in contrast group of 20 science classes ( 5 teachers and 466 students). The results suggest that a systems design approach for teaching science concepts has superior performance in terms of knowledge gain achievements in core science concepts, engagement, and retention when compared with a guided inquiry approach. The systems design approach was most helpful to low-achieving African American students.

\section{Introduction}

What does student performance look like using an authentic design task to teach science concepts when examined concurrently with a scripted inquiry approach to do the same? For this project, the authors developed, disseminated, implemented, and evaluated a module for building electrical alarm systems in order to teach students electricity concepts in science classes.

Design-based learning is intended to engage students in ways that enhance their abilities to solve real-life problems and to reflect on their learning processes. This style of active learning is an extension of project-based learning, which is argued to enable students to relate problems to science concepts. ${ }^{10,15}$ Design-based learning differs from project based learning in that, in addition to constructing and building, students engage in a design and planning process that follows engineering design.

Typically, as was the case in the subject school district, electricity (and science in general) is taught using a guided/scripted inquiry approach to learning. Students are given materials and procedural scaffolding that is intended to help them "discover" properties of electricity and electrical (scientific) principles, such as voltage, resistance, and current in different electronic components using multi-meters. Such an approach is central to the design of many science classroom learning materials and environments, such as the Full Option Science System (FOSS), as was the case in the subject school district. This contrasts with the design-based immersion approach, which begins with providing scaffolding for students to solve a problem that is relevant to their lives and that connects to the electricity (science) topics. The intention of immersion units ${ }^{14}$ of the sort in this paper is to provide an in-depth experience for learning science. The researchers wanted to explore how a systems design approach affects student performance when compared/contrasted with the scripted inquiry approach. In addition, they wanted to investigate whether a systems design approach could reduce achievement differences. 


\section{A Systems Design Approach}

The Electrical Alarm System: Design, Construction and Reflection learning module was developed in the winter of 2003 - 2004 collaboratively with the science program officer and the supporting science curriculum team and with teachers. In addition to meeting state standards involving electricity concepts, the module was designed specifically to address two state and national standards for which the district requested assistance. One standard addresses the issue of design: Know and use the technological design process to solve a problem. The other, systems thinking: Explain the parts of a simple system and their relationship to each other. The module was designed to supplement and partially replace $4-5$ weeks of instruction in the FOSS unit on electricity.

The authors developed a student guide and teachers guide to provide reading and scaffolding materials. During implementation, the authors conducted as series of 5 professional development workshops, which addressed issues of background, pedagogy, and implementation; sharing of experience issues; reflection; and assessment. The researchers provided on-site guidance through extensive classroom visits, during which they maintained an ethnographic log account of classroom dynamics, and a complete video record of implementation in four classes at one school.

Students and teachers followed a systems design approach ${ }^{3,11,16}$ throughout the course of the 4 5 week implementation. Based on authentic approaches that systems engineers use in the design and analysis of systems, the design approach ${ }^{2,4}$ consisted of the following major stages: 1 . Describe current situation; 2. Identify needs; 3. Develop criteria; 4. Generate alternatives; 5. Make selection/choose an alternative; 6. Construct prototype; and 7. Reflect and evaluate. These seven stages of systems design and analysis were generated from the researchers' past experience in systems engineering and design, supplemented by a review of the best practices of empirical studies of design. In a typical system design implementation, the reflect and evaluate stage would involve going back through the entire process iteratively in order to improve and adjust the design specifications as new knowledge and problems are encountered. Although it was not possible to have students repeat a complete second iteration of the entire process, scaffolding for both the students and the teacher encouraged students to go back, review, re-use, and refine what they had produced and documented in earlier stages of this overall process.

The researchers provided scaffolding for students to work both individually and in teams for each of the stages of their design process. This issue of providing a framework in which students can pursue their own ideas is one of the main differences between a systems design approach when compared and a scripted inquiry approach. The systems design approach is organized according to modes of different types of thinking. For example, thinking about needs, requirements, alternatives, and decision criteria involves generative and analytical thinking. Thinking about system parameters such as materials, energy and information inputs and outputs involves analytical thinking and synthesis thinking. Thinking about alternative designs and choosing a design involves evaluative thinking. In the systems design approach, inquiry into scientific materials, methods, and principles becomes another mode of thinking in a scaffolded series of modes of thinking. 
The infusion of science concepts, through inquiry, occurred mainly during the final two stages of the systems design process, and was left rather unscripted, except for scaffolding documentation for which students needed to draw their circuit attempts and explain them during the process of building. The teacher was encouraged only to explain a science concept to a student only after that student had made several attempts at exploring the concept and trying different ideas and configurations during circuit construction. This is in major contrast with the scripted inquiry approach, which provides step-by-step instructions for most aspects of an investigation. Scripted inquiry is mainly organized according to the presentation of science concepts in a way chosen by curriculum designers instead of by modes of thinking. Major differences between the systems design approach and the scripted inquiry approach is the amount of time students spend on tasks associated directly with science concepts and the amount of depth to which science concepts are explored.

It was the position of the authors that the potential student benefits, supplemented with teacher professional development training and implementation support would mitigate the risks and achieve overall increases in student performance under the systems design approach. Prior work with design-based learning has found that it can produce conceptual learning, ${ }^{1,5,6,12}$ but it has not previously been contrasted directly against scripted inquiry. This paper presents a study designed to test this contrast.

Finally, a note on the systems design approach and performance and equity gaps. In addition to having generally low performance, K-12 science education in the US generally produces large differences between low and high SES students, as well as between Caucasian or Asian students and Latino and African American Students ${ }^{7,8}$. Moreover, beginning in middle school and growing in high school, there is a significant difference between male and female performance in

science. ${ }^{7}$ Permitting students to choose what they design may reduce equity gaps. In addition, students needed to present their ideas to one another, and this was viewed as facilitating a process whereby students take ownership of their ideas, which also is expected to contribute to reducing equity gaps in performance. Another equity gap issue involves equal access to materials for construction. The researchers created the systems design learning module in such a way that all hands-on work occurred in the classroom, using the same sets of materials for all students (this is the same as scripted inquiry). Such a configuration is not always the case for projectbased learning. When students are permitted to use materials from home, performance differences can be exacerbated because of unequal access to resources and to available time outside of class. The systems design module used many of the same materials that were already part of existing scripted inquiry kits and was supplemented with an additional kit of buzzers, photocells, and thermistors.

\section{Methodology and Data Collection}

The researchers used a paired experimental/contrast design in which 10 teachers and 587 students (26 classes) implemented the system design approach with the Alarm System module, and 5 teachers and 466 students (20 classes) followed the scripted inquiry approach with the scripted inquiry Electricity unit. Both groups were recruited from the entire pool of 27 science 
teachers for $8^{\text {th }}$ grade in an urban school system in the Northeast US. The authors offered the entire pool of $8^{\text {th }}$ grade science teachers an opportunity to learn about systems design-based learning during a professional development workshop at the very beginning of the spring 2004 term. This workshop was one option among more than five others available to the teacher pool. Teachers were strongly encouraged to engage in some form of professional development training by the district, although such training was not required. 19 teachers attended the workshop, and 12 initially agreed to participate in the experimental condition. Two teachers could not participate in the study for various administrative reasons. The remaining 10 teachers were therefore self-selected, although not purely voluntarily, because of the district's encouragement to participate in some form of professional development, because the teachers were paid for their time spent in professional development training at the district rate for PD compensation, and because the teachers earned PD continuing education credits. The teachers were informed that they could discontinue their participation at any time for any reason.

The contrast group was recruited from the remaining teachers in the district. The authors sent a letter of request (and testing materials) to the remaining teachers to administer pre and post tests as part of this research study. The district science program officer also sent a request for participation, although there was not a specified requirement to do so. From the remaining pool, 7 teachers returned pre-test results and 7 post-test results, although there were different schools in the two pools. There were 5 teachers common to both groups, and they make up the contrast group. The contrast group thus consisted of a more volunteer-oriented composition than the experiment group because there was less district encouragement, no compensation offered, and no certification credit granted to participate as a contrast group member.

The differences in incentives between experiment and contrast groups were expected to bias performance against the experiment group. The teachers in the contrast group who decided to participate would only be among the most motivated and most competent teachers who were comfortable taking on an additional comparison evaluation activity with little incentive.

This selection procedure resulted in some demographic differences between the experimental and contrast group from the schools that reported such data. In terms of overall socioeconomic status (SES) information based on district data for each of the schools, the contrast group has a higher proportion of students from schools in the low SES range (53\% of 587 students vs. 32\% of 466 students). The SES categories are based on proportion of students considered by the district to be economically disadvantaged, with the low group having schools with more than $66 \%$ of their students economically disadvantaged, the high group having less than $40 \%$, and medium the interim proportion. The four lowest SES schools in the district are in the experiment group. This difference is offset by a lower proportion of students in the middle SES range (14\% vs. 38\%). The groups are nearly evenly matched among students in the high SES range. In terms of gender, the experiment group had a slightly higher proportion of female students (54\% vs. 51\%), a twice-as-high proportion of African American students (66\% vs. 33\%) and a higher proportion of students receiving free and/or reduced lunches (64\% vs. 58\%).

Students were given pre and post tests to measure changes in student knowledge of electricity concepts. The researchers specifically created a knowledge test that was designed around core 
concepts in electricity, such as resistance, current, voltage, series and parallel circuits in order to ensure that both experiment and contrast groups would be evaluated on content knowledge on which the guided inquiry approach focused.

V. Results

Overall, the experiment group achieved twice the pre-post gains in scores on science knowledge content questions when compared with the contrast group, as Figure 1 shows. The experiment group showed a mean gain of $16 \%$ versus the contrast group gain of $7 \%(t=2.02 ; p<0.01)$. This analysis involved calculating a mean for each classroom, computing classroom gains, and then comparing differences in mean classroom gain by condition. Here, and in later analyses, effect sizes are shown on the figure, and are calculated as the difference in mean condition gains divided by the pooled standard deviation in gains.

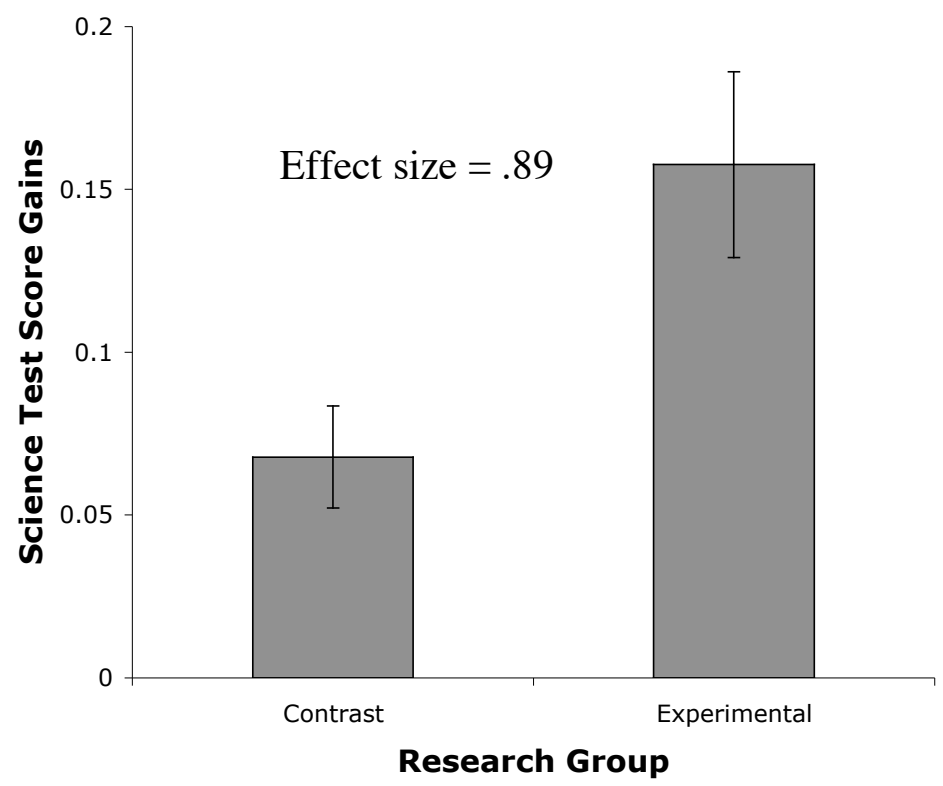

Figure 1: Mean Pre-Post Gains on Science Concepts Test by Group, with Standard Error Bars

The experiment group started at an overall lower mean science knowledge pretest score (0.29) than the contrast group (0.38). The differences in initial test scores may likely be explained by the differences in the socioeconomic status between the experiment and contrast group schools and the teacher selection process. The gap in overall performance decreased, from the initial difference of 9 test percentage points to essentially parity in performance, with less than 1 test percentage point difference, with the experiment group having a final overall mean test score of 0.45 and the contrast group with a final overall mean score of 0.46 .

The systems design approach produces better gains overall. What about its impact on equity gaps? As Figure $2 A$ shows, the science knowledge test gains for African American students in the experiment group are eight times higher $(\mathrm{M}=0.16$ vs. $0.02 ; \mathrm{t}=2.05, \mathrm{p}<0.01)$ than the 
contrast group. Non-African American students in the experiment group achieved nearly double the score gains than the contrast group $(\mathrm{M}=0.21$ vs. $0.11 ; \mathrm{t}=2.06, \mathrm{p}<0.07)$. Thus, the systems design approach does not completely eliminate the gap, but it does move African American students from a position of almost no learning to better learning than the non-African American students were showing in the contrast group.

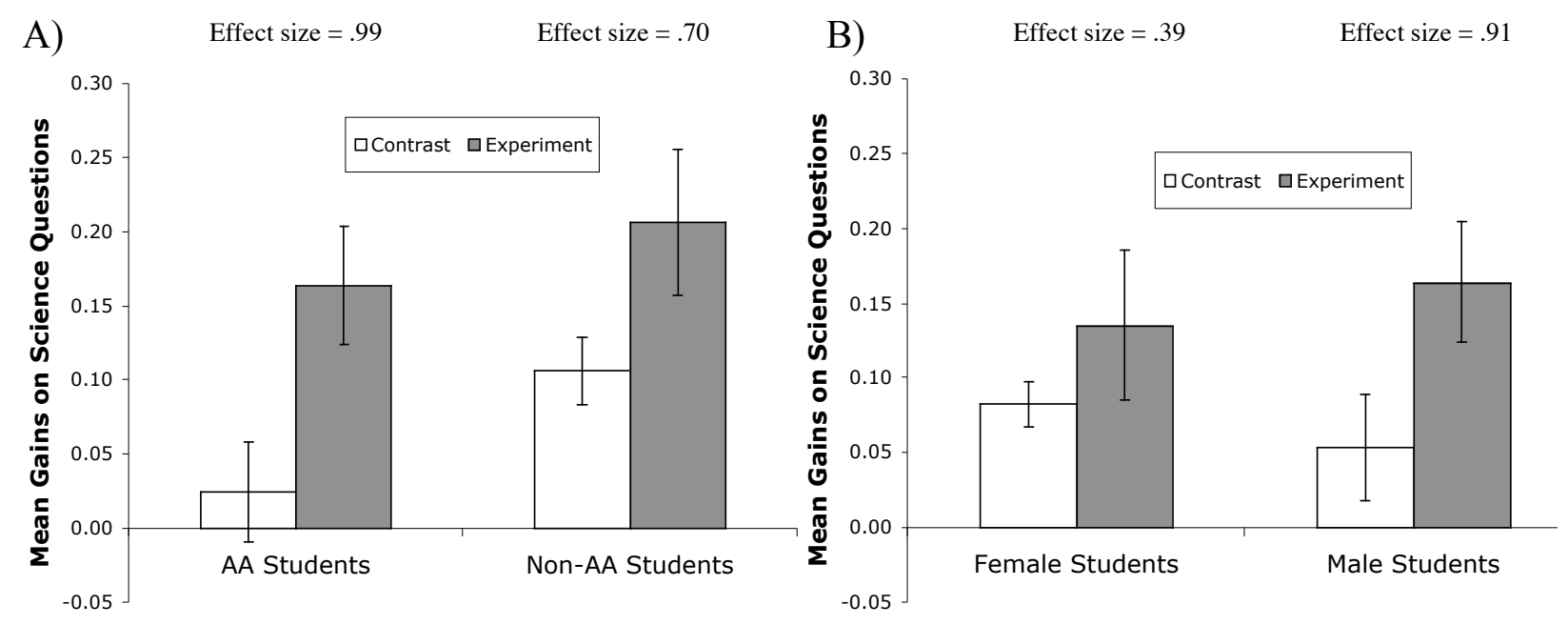

Figure 2: A) Mean Pre-Post Gains on Science Test by Race and Group (and SE bars), and B) Mean Pre-Post Gains on Science Test by Gender and Group (and SE bars)

Figure $2 B$ shows the gains that males and females achieved for both experiment and contrast groups. Gains for females and males in the systems design group were nearly identical $(0.14$ for females; 0.16 for males), well within the range of measurement uncertainty. These results suggest that the systems design approach does not produce any performance gaps according to gender. Male students using the systems design approach achieved significant gains when compared with their counterparts who followed the scripted inquiry approach $(\mathrm{M}=0.16 \mathrm{vs} .0 .05$; $\mathrm{t}=2.04, \mathrm{p}<0.01)$. Female performance gains were higher for the systems design approach, although not significantly so $(\mathrm{M}=0.14$ vs. $0.08, \mathrm{t}=2.03, \mathrm{p}<0.25)$.

The systems design approach had the biggest impact on low-achieving African American students in terms of science knowledge test performance. Students were grouped into 3 performance categories according to their scores, with low achievement defined as scores lower than $30 \%$, moderate as scores between $30-60 \%$, and high as scores over $60 \%$ correct on science questions.

As Figure 3 shows, the African American systems design group showed upwards shifts for all performance categories, with a shift of $21 \%$ of its population out of the low achieving category to higher categories, and with an increase of $15 \%$ of the entire population into the highest performance category. By comparison, the contrast group showed a small increase in the proportion of students in the low achieving category. What this finding suggests is that the systems design approach may be particularly effective for reaching this demographic group. 


\section{Discussion}

What does student performance look like using an authentic design task to teach science concepts when examined concurrently with a scripted inquiry approach to do the same? From an overall performance perspective, the gains in test scores across all performance group categories when compared with the scripted inquiry approach appear to be appreciable. This result takes on additional meaning when viewed from the perspective of time-on-task for electricity (science) concept activities. For the systems design group, a tabulation of time spent on science concepts from observation logs shows that students spent about $2 / 3$ of their time on science concepts. This contrasts with the guided inquiry approach, for which nearly all of the module's time was spent on science concepts.

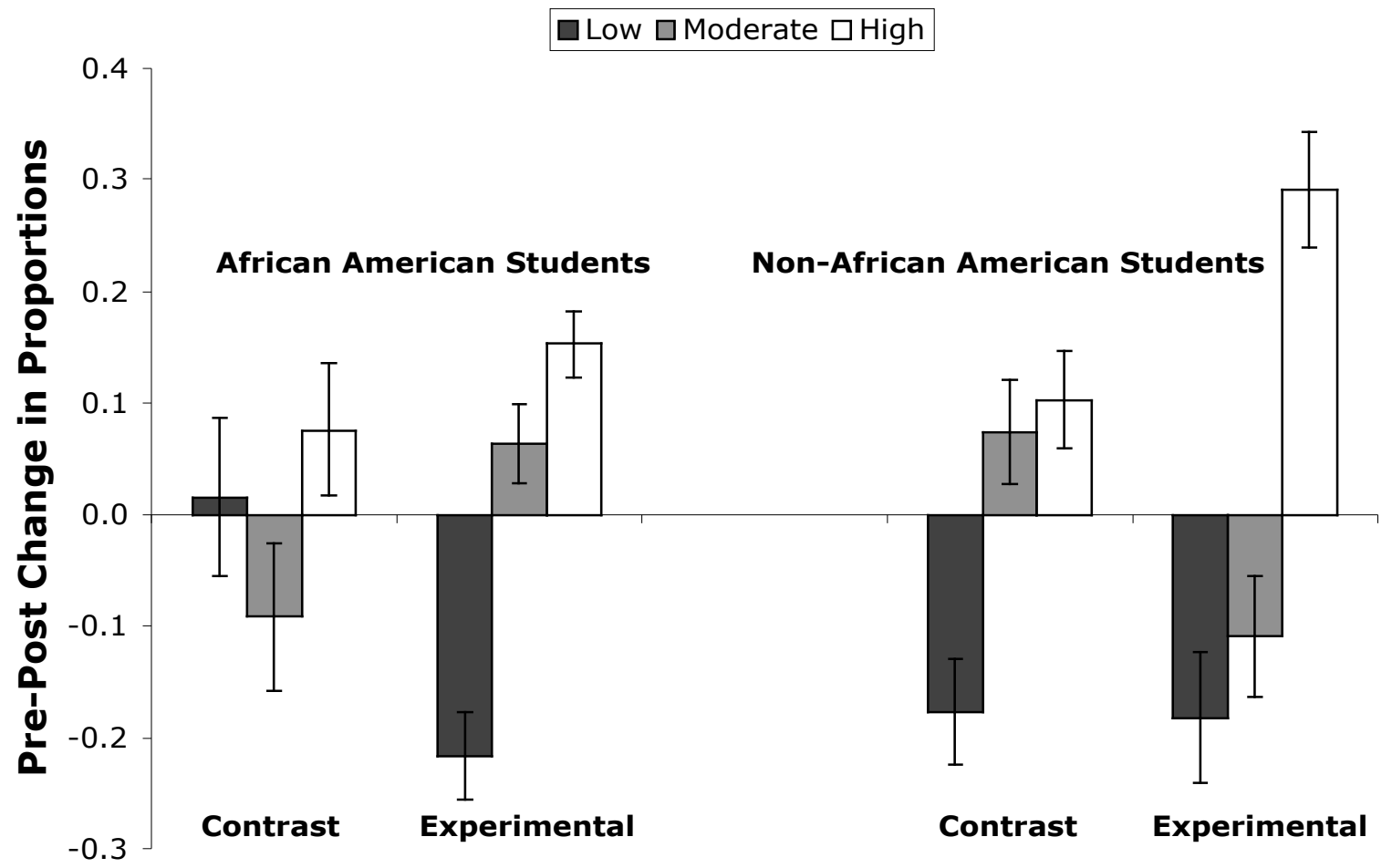

Figure 3: Mean Pre-Post Change in Proportion of Students in Low/Medium/High Science Test Performance Categories by Race and Group (with SE bars)

What this result reveals is that the systems design approach achieves more gains in science concept knowledge while spending much less time on the concepts. This finding is consistent with other such findings. ${ }^{13}$ In addition, retention has been reported to be stronger when using problem-based approaches. ${ }^{9}$ Therefore, there is support to suggest that the systems design approach has superior performance in terms of time spent on concepts, knowledge gain achievements, engagement and retention when compared with a guided inquiry approach. 
Bibliography

1. Barton, A. C. (1998). Examining the social and scientific roles of invention in science education. Research in Science Education, 28(1), 133-151.

2. Blanchard, B. \& Fabrycky, W. B. (1998). Systems Engineering and Analysis. Prentice Hall.

3. De Bono, E. (1986). The CoRT Thinking Program (2nd ed.). Oxford: Pergamon Press.

4. Gibson, E. J. (1968). Introduction to Engineering Design. New York: Holt, Rhinehart, and Winston.

5. Kolodner, J. L. (2002). Facilitating the learning of design practices: Lessons learned from inquiry into science education. Journal of Industrial Teacher Education, 39(3).

6. Kolodner, J. L., Crismond, D., Fasse, B. B., Gray, J. T., Holbrook, J., Ryan, M., et al. (2003). Problem-based learning meets case-based reasoning in the middle-school science classroom: Putting a Learning-by-Design curriculum into practice. Journal of the Learning Sciences, 12(4), 495-548.

7. Martin, M. O., Mullis, I. V. S., Beaton, A. E., Gonzalez, E. J., Smith, T. A., \& Kelly, D. L. (1997). Science achievement in the primary school years: IEA's third international mathematics and science study. Chestnut Hill, MA: Center for the Study of Testing, Evaluation, and Educational Policy, Boston College.

8. Martin, M. O., Mullis, I. V. S., Gonzalez, E. J., Gregory, K. D., Smith, T. A., Chrostowski, S. J., et al. (2000). TIMSS 1999 international science report: Findings from IEA's repeat of the third international mathematics and science study at the eighth grade. Chestnut Hill, MA: International Study Center, Lynch School of Education, Boston College.

9. Norman, G. \& Schmidt, H. (1993). The Psychological Basis of Problem-Based Learning: A Review of Evidence. Academic Medicine, 67, 557- 565.

10. Prince, M. (2004). Does Active Learning Work? A Review of the Research. Journal of Engineering Education. 93 (3), $223-232$.

11. Penner, E. D. (2001). Complexity, Emergence, and Synthetic Models in Science Education. In: K. Crowley, C. D. Schunn, \& T. Okada (Eds.) Designing for Science, Mahwah, NJ: Lawrence Earlbaum Associates.

12. Penner, D. E., Lehrer, R., \& Schauble, L. (1998). From physical models to biomechanics: A design-based modeling approach. Journal of the Learning Sciences, 7(3-4), 429-449.

13. Redish, E., Saul, J. \& Steinberg, R. (1997). On the Effectiveness of Active-Engagement Microcomputer-Based Laboratories. American Journal of Physics, 65 (1), 45.

14. Schunn D. C., Millar, T. \& Lauffer, D. (2005). SCALE Goal 2 Concept Paper: Immersing All K-12 Students in Extended Inquiry, Science and Design. Madison, WI and Pittsburgh, PA: University of Wisconsin and University of Pittsburgh.

15. Thomas, W. J. (2000). A Review of Research on Project-Based Learning. San Rafael, CA: The Autodesk Foundation.

16. Wiggins, G. \& McTighe, J. (1998). Understanding by Design. Merrill Education/ASCD College Textbook Series, ACSD, Alexandria, Virginia. 